\title{
NONDESTRUCTIVE ASSAY (NDA) OF FISSILE MATERIAL SOLUTIONS IN TANKS AT ROCKY FLATS ENVIRONMENTAL TECHNOLOGY SITE
}

\author{
I. G. Fleissner, F. W. Lamb, and M. R. Maul, \\ Safe Sites of Colorado, Rocky Flats Environmental Technology Site, \\ P.O. Box 464, Golden, CO 80402-0464, 303-966-5325
}

\begin{abstract}
Nondestructive assay of holdup in solution tanks at Rocky Flats has been performed to address criticality safety concerns since 1974. Destructive analysis techniques were used for quantification of the fissile material content of the tanks. With termination of operations in 1989, including sparging and sampling of tanks, a need arose for nondestructive assay of solutions in tanks to confirm previous inventory values. Gamma ray measurement methodologies were investigated and several techniques, including Poor Man's Densitometry were implemented. These techniques have been applied to several different types of tanks including: annular, raschig ring filled, and pencil tanks. For the annular tanks "Poor Man's Densitometry" is used, with the densities of the measured solutions normalized to the value of one "accepted" concentration tank. Measurement uncertainties for this technique has been better than was anticipated. Measurements are also performed at several levels to attempt to detect variations in density. For the current tank draining program, solution in tanks is assayed by the NDA gamma-ray technique before draining. Measurement results were obtained for plutonium, uranium, and mixtures of $\mathrm{U} / \mathrm{Pu}$ solutions for concentrations ranging from less than $0.5 \mathrm{~g} / 1$ to $150 \mathrm{~g} / 1$. Tanks with expected concentrations were used to establish a relationship between concentration and count rate. "Bootstrapping" calibration techniques were used in some cases to obtain quantitative results.
\end{abstract}

\section{INTRODUCTION}

Nondestructive assay (NDA) measurements for holdup of fissile materials in solution tanks at Rocky Flats have been performed since 1974 to address criticality safety concerns. Destructive analysis techniques, however, were used for quantification of the fissile material solution content of the tanks.
With termination of operations at Rocky Flats in 1989 , tasks such as tank sparging and sampling were also halted. This led to a need for a non-intrusive method to quantify the solution content in tanks in order to confirm inventory values. Clearly NDA techniques were the "solution" to the measurement problem. Gamma-ray measurement methodologies were investigated and several approaches, including "Poor Man's Densitometry"1, were implemented. These measurement approaches have been applied to several different types of tanks including: annular tanks, raschig-ring filled tanks, pencil tanks, and small volume cylindrical tanks.

All the quantitative concentration measurements were performed with a small volume $\left(14 \mathrm{~cm}^{3}\right)$ hyperpure germanium (HPGe) gamma-ray detector. The detector is shielded and collimated with a lead/tungsten fixture having a circular aperture 3/4 inch in diameter by 1 inch deep. This detector is also used for holdup measurements and has been calibrated for point, line, and area sources. This information was useful at times when efficiency calibration data for the detector was needed. The spectral data were collected using portable multichannel analyzers and laptop computers.

For the current liquid stabilization program, nuclear safety reasons require that the solution in the tanks be assayed by NDA before draining and sampling. In addition, for nuclear safety and accountability purposes, gamma-ray measurements are performed at several solution heights in the particular tank to attempt to detect variations in density. Measurement results are required for plutonium, uranium, and mixtures of $\mathrm{U} / \mathrm{Pu}$ solutions. Where possible, tanks with "expected" concentrations or previous DA sampling concentration values were used to establish a preliminary relationship between concentration and count rate. For some tanks, process knowledge or "guess-timates" were the only source of concentration 


\section{DISCLAIMER}

Portions of this document may be illegible in electronic image products. Images are produced from the best available original document. 
information prior to the NDA measurements. As tanks are drained and sampled this information is used to "bootstrap" tank calibrations to improve the quantitative results.

\section{ANNULAR TANKS AND "POOR MAN'S DENSITOMETRY"}

Subsequent to the 1989 termination of operations at Rocky Flats, the initial measurement need for solution concentration measurements was for four high concentration, plutonium nitrate $(100-200 \mathrm{~g} / \mathrm{l})$, annular tanks in Building 771. These tanks were used to support the oxalate precipitation process and represented the highest $\mathrm{Pu}$ concentration tanks at Rocky Flats. Previous DA sampling results were available for the $\mathrm{Pu}$ concentration values; however, new measurements were required for inventory purposes. Table I shows the dimensions of the four tanks. Gamma-ray spectra were collected in contact with the tank wall and at four different points on each of the annular tanks. These points are barcoded so that subsequent measurements can be made at the same locations on the tank. The energy range of the gamma-ray spectra was from about $40 \mathrm{keV}$ to $500 \mathrm{keV}$.

Table I. Dimensions for high concentration Pu nitrate annular tanks

\begin{tabular}{||c|c|c|c||}
\hline Tank & Diameter & Height & $\begin{array}{c}\text { Annular } \\
\text { Thickness }\end{array}$ \\
\hline 550 & $36^{\prime \prime}$ & $111^{\prime \prime}$ & $1.5^{\prime \prime}$ \\
\hline 931 & $60^{\prime \prime}$ & $82^{\prime \prime}$ & $13 / 8^{\prime \prime}$ \\
\hline 933 & $42^{\prime \prime}$ & $83^{\prime \prime}$ & $13 / 8^{\prime \prime}$ \\
\hline 1810 & $36^{\prime \prime}$ & $87^{\prime \prime}$ & $2^{\prime \prime}$ \\
\hline
\end{tabular}

Initially, several measurement difficulties were readily apparent for the planned assay of the annular tanks. First, due to the curtailment of nuclear material activities at Rocky Flats in 1989, no calibration standards for the tanks were available nor could any be prepared. Secondly, the tanks are in "farms" of other tanks, such that high radiation backgrounds could be expected. Also, an external transmission source is typically used in gamma-ray density measurements to correct for matrix effects ${ }^{2}$. Technical difficulties of access and alignment precluded the use of a transmission source on these tanks. Finally, the four annular tanks do not have exactly the same diameters, heights, or annular thicknesses. The assay method chosen would have to be robust enough to be fairly insensitive to matrix, geometry, and background effects.

The NDA method finally selected for the density measurements of the annular tanks was the "Poor Man's Densitometry" (PMD) technique. This technique had been used previously for $\mathrm{Pu}$ solution in vials or bottles. ${ }^{1}$. However, it had not been used for tanks. Several factors make the technique attractive for measurement of annular tanks: it does not require a transmission source, it is fairly insensitive to matrix effects, it is calculationally simple, and - since it relies on ratios of peaks - it is not sensitive to many potential biasing effects. In fact, the method is not count time dependent.

The "Poor Man's Densitometry" technique utilizes the ratio of an $\mathrm{x}$-ray $(111 \mathrm{keV})$ and a gamma ray (129 $\mathrm{keV}$ ) on opposite sides of the $\mathrm{Pu} \mathrm{K}$ absorption edge $(122 \mathrm{keV})$. This results in a significant difference in the mass absorption coefficients for the two lines. The ratio of the intensities for the 111 and 129 spectral peaks is therefore very sensitive to the $\mathrm{Pu}$ density (grams $\mathrm{Pu}$ per liter of solution). The TRIFID/EPICS isotopic code ${ }^{3}$ was used to extract the spectral intensities for the two peaks. Since the $129 \mathrm{keV}$ peak is a singlet peak, its area can be extracted relatively easily. However, more caution is needed for the $111 \mathrm{keV}$ peak area extraction. This peak is part of a 13 peak multiplet of x-rays and gamma rays and therefore the TRIFID/EPICS code was required for the proper deconvolution. Figure 1 shows the spectral region used for this analysis.

The experimentally measured $111 / 129$ peak ratios for the four tanks were found to be a fairly linear function of the previously known destructive analysis (DA) density values. Since no calibration standards were available, an absolute calibration factor could not be determined. Therefore it was decided to use one tank (Tank 550) as a single calibration, or normalization point. Measurement precision has closely tracked the counting statistics uncertainty. Currently the PMD measurements of the four tanks are being performed on a bimonthly basis. 


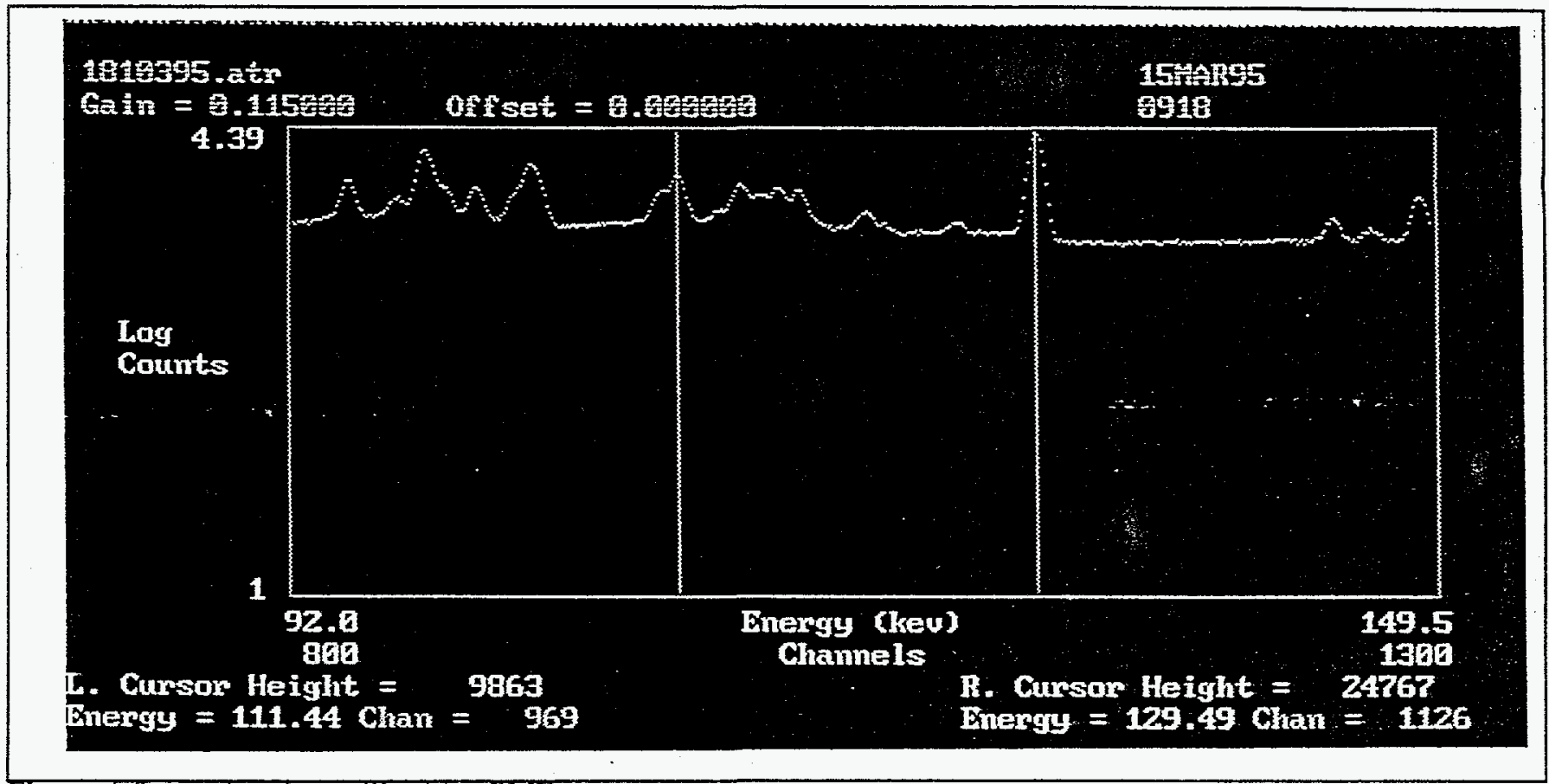

Figure 1 Spectral region utlized for PMD measurements

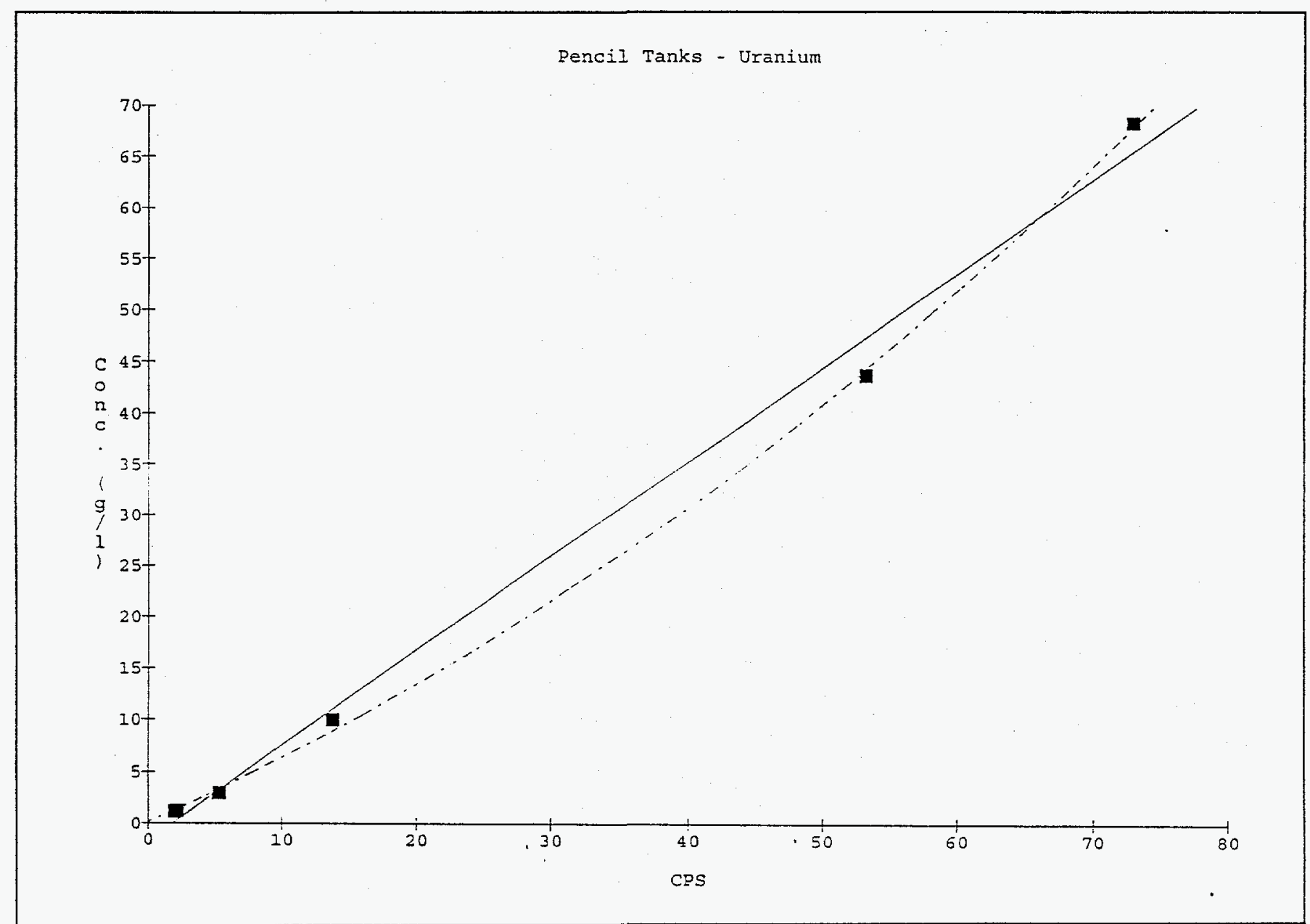

Figure 2 Count rate vs. concentration, uncorrected for self-absorption 
Table II shows the results of 18 separate PMD measurements compared to the "accepted" values. Good agreement is obtained; however, the lower concentration tanks (Tanks 931 and 933) exhibit a high bias of about $6-10 \%$. For high $\mathrm{Pu}$ concentrations of these thicknesses ( 1.5 - 2 inches), it would be reasonable to expect that the calibration curve would exhibit some non-linearity in this concentration region. To confirm this, the tanks were modeled using the code MicroShield v4.22. The modeling results indicate an expected bias of about $8 \%$, in good agreement with the observed bias. With proper calibration standards this non-linearity could be incorporated into a calibration curve. The highest concentration tank, Tank 1810 , shows a low bias of $5.4 \%$. This tank has an annular region thickness of 2 inches whereas Tank 550 is 1.5 inches. Once again good agreement is found through modeling - the effect of the thickness difference was found to be $4.4 \%$.

An interesting feature of the detector configuration was noted during the spectral data analysis. For each annular tank measurement, a background spectrum is obtained. This spectrum is obtained at the assay point after inserting a one inch lead plug into the detector aperture. This procedure will give an indication of gamma-ray leakage through the side shields and from behind the detector. No indication of leakage was found at 111 or $129 \mathrm{keV}$ in the background spectra - the shields are thick enough at these energies that the high background is not a problem and no correction is needed. However, at higher energies, e.g. $414 \mathrm{keV}$, leakage was observed and corrections for background would be required.

\section{PENCIL TANKS}

Confirmatory assays were required for six pencil tanks in Building 771. These tanks are six inch diameter, vertical, critically-safe-by-geometry tanks. These tanks were known to have primarily solutions of high enriched uranium, ranging from 1 to $70 \mathrm{~g} / 1$ of ${ }^{235} \mathrm{U}$. Some of the tanks were known to contain small concentrations of plutonium. These tanks had supported the uranium precipitation batch process.

Unlike the Pu case, no suitable gamma-rays or x-rays are available for the PMD technique. Therefore the $186 \mathrm{keV}$ line of ${ }^{235} \mathrm{U}$ was utilized as the assay
Table II: Annular tank assay results from PMD

\begin{tabular}{||c|c|c|c|c||}
\hline \multirow{2}{*}{ DATE } & \multicolumn{5}{|c|}{ Concentration (g/l) } \\
\cline { 2 - 5 } & $\begin{array}{c}\text { Tank } \\
550\end{array}$ & $\begin{array}{c}\text { Tank } \\
931\end{array}$ & $\begin{array}{c}\text { Tank } \\
933\end{array}$ & $\begin{array}{c}\text { Tank } \\
1810\end{array}$ \\
\hline \hline $12 / 90$ & 130.3 & 104.8 & 98.0 & 131.3 \\
\hline $2 / 91$ & 130.3 & 108.4 & 101.4 & 133.2 \\
\hline $3 / 91$ & 130.3 & 101.1 & 98.8 & 124.6 \\
\hline $12 / 91$ & 130.3 & 104.9 & 102.8 & 132.3 \\
\hline $12 / 92$ & 130.3 & 106.5 & 100.1 & 133.8 \\
\hline $3 / 93$ & 130.3 & 105.3 & 100.1 & 134.2 \\
\hline $6 / 93$ & 130.3 & 114.0 & 102.3 & 130.0 \\
\hline $9 / 93$ & 130.3 & 104.6 & 102.8 & 126.6 \\
\hline $11 / 93$ & 130.3 & 105.8 & 98.0 & 133.4 \\
\hline $1 / 94$ & 130.3 & 103.3 & 97.5 & 130.4 \\
\hline $3 / 94$ & 130.3 & 113.7 & 98.7 & 135.7 \\
\hline $5 / 94$ & 130.3 & 110.5 & 104.6 & 136.5 \\
\hline $7 / 94$ & 130.3 & 104.1 & 99.0 & 138.4 \\
\hline $9 / 94$ & 130.3 & 104.7 & 98.5 & 133.4 \\
\hline $11 / 94$ & 130.3 & 105.2 & 101.5 & 134.9 \\
\hline $1 / 95$ & 130.3 & 106.7 & 99.6 & 135.0 \\
\hline $3 / 95$ & 130.3 & 108.6 & 101.3 & 133.8 \\
\hline $5 / 95$ & 130.3 & 107.6 & 102.7 & 134.7 \\
\hline & & & & 140.1 \\
\hline Mean: & 130.3 & 106.7 & 100.4 & 132.9 \\
\hline RSD: & & 3.2 & 2.1 & 2.5 \\
\hline DA: & 130.3 & 96.1 & 94.8 & $140 . \mid$ \\
\hline
\end{tabular}

measurement peak. Spectral measurements were obtained in contact with the tank wall and at three different heights for each tank. A ${ }^{133} \mathrm{Ba}$ source was utilized to provide dead time correction for each spectrum. The TRIFID/EPICS code was used to extract the intensities of the $186 \mathrm{keV}{ }^{235} \mathrm{U}$ line and the $129 \mathrm{keV}$ and $414 \mathrm{keV}{ }^{239} \mathrm{Pu}$ lines. 
The corrected count rate for the $186 \mathrm{keV}$ line was plotted as a function of the $D A{ }^{235} \mathrm{U}$ concentration (grams ${ }^{235} \mathrm{U}$ per gram solution). The results are shown in Figure 2. The non-linearity of the relationship is due to the self-absorption of the 186 $\mathrm{keV}$ gamma-rays in the solution. (Increasing solution density leads to increasing gamma-ray self absorption). To correct for this effect, a self-

Table III: Pencil tank assay results

\begin{tabular}{||c|c|c||c|c||}
\hline $\begin{array}{c}\text { Tank } \\
\#\end{array}$ & $\begin{array}{c}\text { Measured } \\
{ }^{235} \mathrm{U} \\
(\mathrm{g} / \mathrm{l})\end{array}$ & $\begin{array}{c}\mathrm{DA} \\
{ }^{235} \mathrm{U} \\
(\mathrm{g} / \mathrm{l})\end{array}$ & $\begin{array}{c}\text { Measured } \\
\mathrm{Pu} \\
(\mathrm{g} / \mathrm{l})\end{array}$ & $\begin{array}{c}\mathrm{DA} \\
\mathrm{Pu} \\
(\mathrm{g} / \mathrm{l})\end{array}$ \\
\hline 1001 & $1.17 \pm 14 \%$ & 1.24 & $0.59 \pm 18 \%$ & 0.38 \\
\hline 1002 & $1.17 \pm 14 \%$ & 1.19 & $0.55 \pm 12 \%$ & 0.44 \\
\hline 1009 & $3.40 \pm 5.0 \%$ & 2.93 & $0.05 \pm 8 \%$ & -- \\
\hline 1010 & $43.9 \pm 0.7 \%$ & 43.85 & $0.09 \pm 10 \%$ & -- \\
\hline 1011 & $68.5 \pm 0.6 \%$ & 68.5 & $0.14 \pm 7 \%$ & 0.12 \\
\hline 1012 & $9.55 \pm 1.9 \%$ & 10.0 & $0.05 \pm 25 \%$ & -- \\
\hline
\end{tabular}

absorption correction factor was calculated for each tank and applied to the $186 \mathrm{keV}$ count rate data. The correction factor equation for a slab was chosen due to the narrow view of the tank by the detector collimator which approximates the shape of a slab. The corrected data are shown in Figure 3. A straight line was fitted to this data and the predicted results are shown along with the "accepted" DA values in Table III. Excellent agreement is obtained with the DA values over almost two orders of magnitude of uranium density. A not-so-obvious dividend of the self-absorption correction is that it is a quasi independent check of the density measurements. Since the magnitude of the correction factors for self-absorption is dependent on the DA concentration value, then if a measured count rate was not consistent with a reported DA value, the data point for that tank would either have been under-corrected or over-corrected and not fallen on the fitted line.

The $\mathrm{Pu}$ densities for these tanks were all very low; less than 1 gram per liter. DA values existed only for three of the six tanks. For the two highest $\mathrm{Pu}$ concentration tanks, the TRIFID/EPICS isotopics code was used to obtain the $\mathrm{Pu} / \mathrm{U}$ ratio. Then using the absolute uranium concentration that had been measured, the absolute $\mathrm{Pu}$ density was determined. The other four tanks had $\mathrm{Pu}$ concentrations about $0.1 \mathrm{~g} / 1$ or less. For these tanks the $129 \mathrm{keV}$ and 414 $\mathrm{keV} \mathrm{Pu}$ lines were used to obtain the assay results.

\section{RASCHIG RING TANKS}

Confirmatory assay measurements have been performed for several raschig ring filled tanks. Raschig rings are rings of borosilicate glass, approximately 1.75 inches long by 1.5 inches in diameter with a $1 / 4$ inch glass annulus. The rings are used in solution tanks to absorb neutrons in order to prevent criticalities in non-geometrically safe tanks. The rings fill the interior of the tank and the solution fills the voids between the rings and the region of the hole in the ring.

The original need for NDA assay of raschig ring filled tanks arose from the need for a concentration value on a tank, Tank 454, which had had "low level" concentration solutions added to it after the last DA sampling was performed. The last known DA value for the tank was approximately $3.0 \mathrm{~g} / \mathrm{l}$.

High resolution gamma-ray spectra were acquired of Tank 454 in contact with the tank at three different points on the tank. Tank 454 is approximately 42 inches in diameter by 5 feet high. The TRIFID/EPICS code was used to extract the intensities of the $111 \mathrm{keV} \mathrm{x}$-ray and the $129 \mathrm{keV}$ and $414 \mathrm{keV}{ }^{239} \mathrm{Pu}$ lines. Two other raschig ring tanks, Tank 452 and Tank 85, were used as calibration points for the Tank 452 measurements. Tanks 452 and 85 were "known" to contain $5.0 \mathrm{~g} / 1$ and $0.75 \mathrm{~g} / 1$ $\mathrm{Pu}$ solutions from previous DA measurements.

Several potential measurement problems are readily apparent for assays of raschig ring tanks. Foremost is the measurement problem the rings themselves present. The rings are oriented randomly in the tanks. It was thought a priori that contact gammaray measurements would give widely differing results for each measurement point on the tank due the varying arrangements of rings and solution in the detector view. This might also confound the data from the calibration tanks when compared to each other and to the unknown tank. An additional problem was that the various raschig ring tanks were of different sizes which would necessitate close 


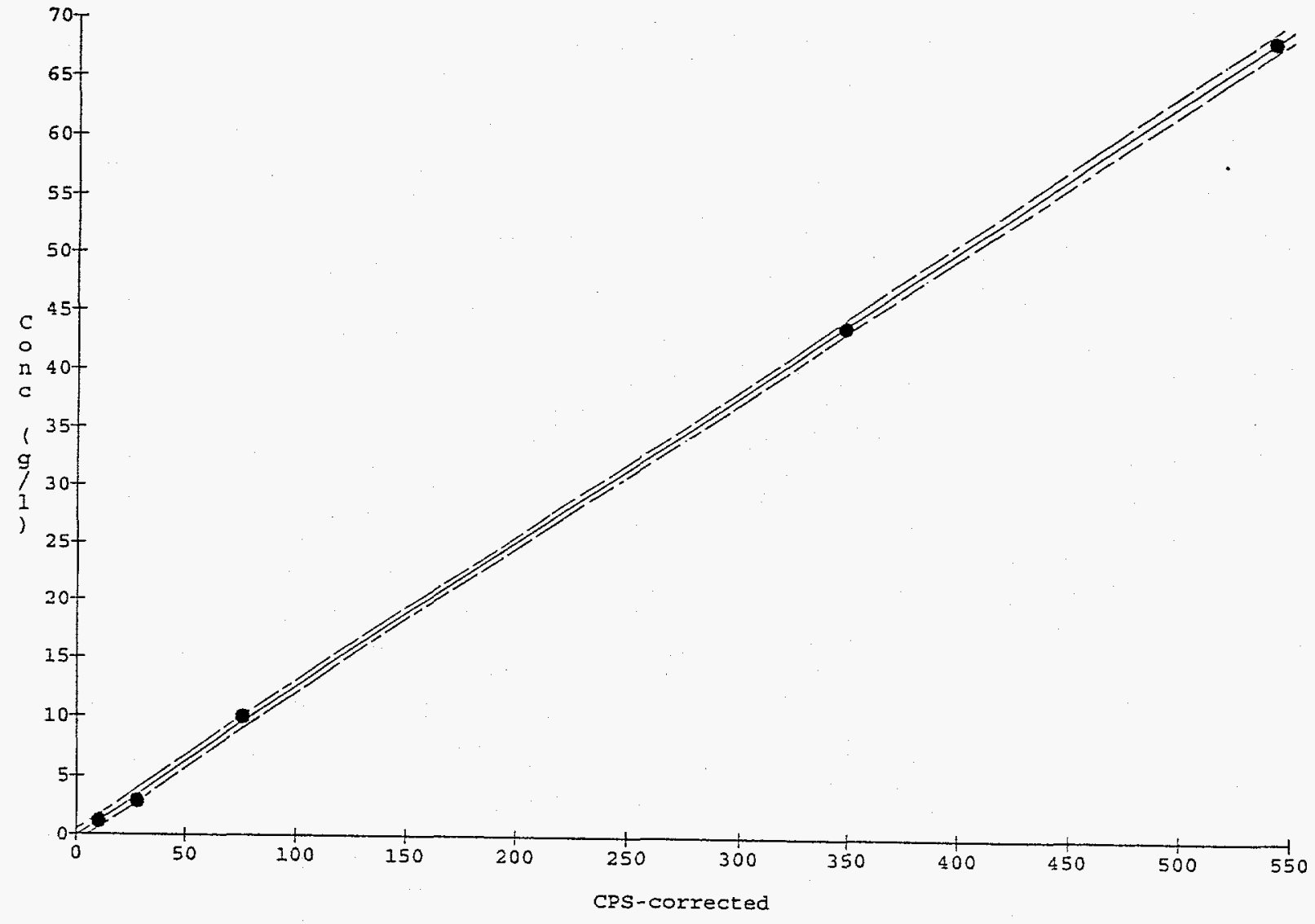

Figure 3 Count rate vs. concentration, corrected for $U$ self absorption

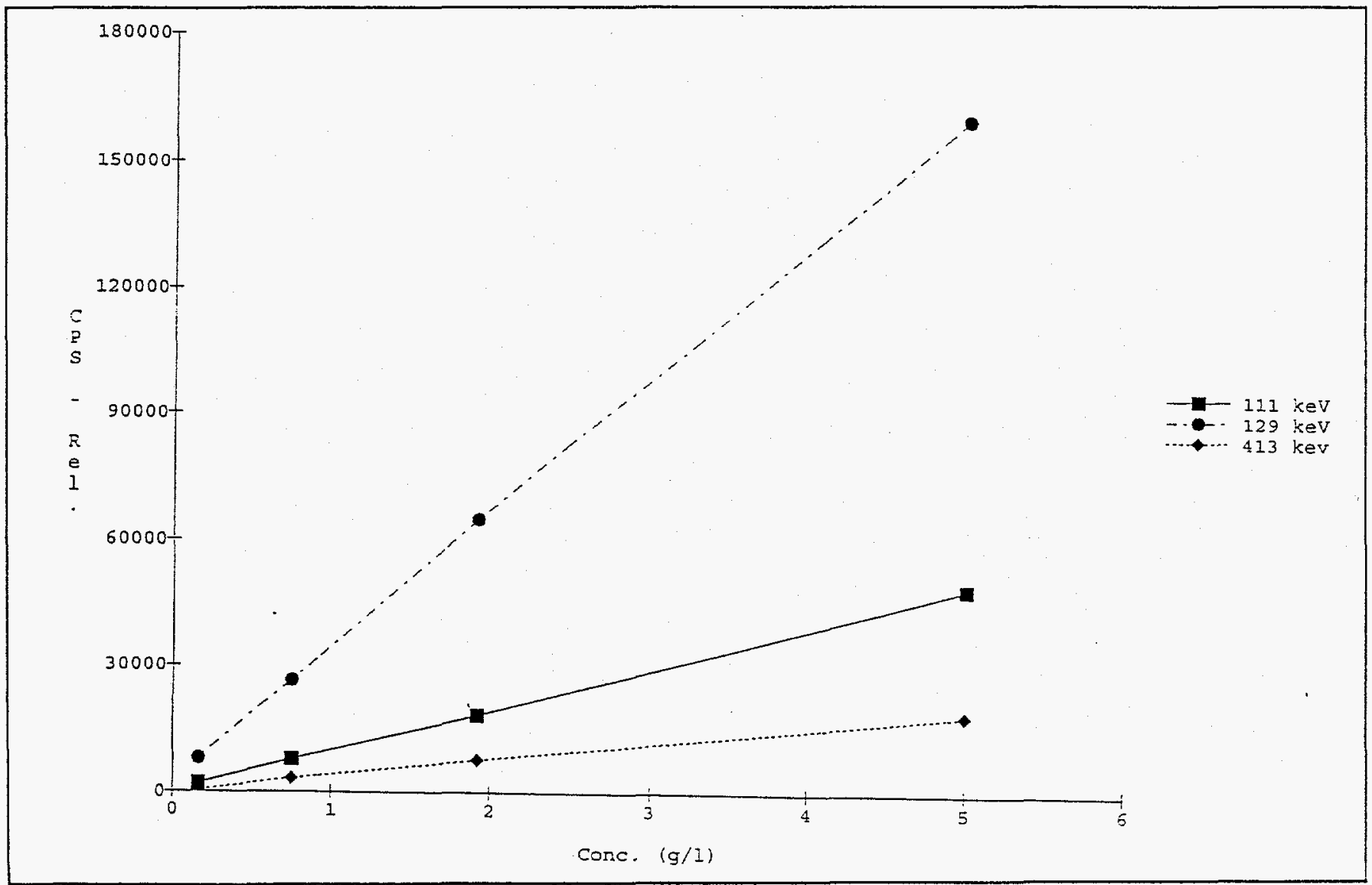

Figure 4 Count Rate vs. concentration for raschig ring tilled tanks 
contact measurements to minimize variations in the data due to geometry effects.

Upon analysis of the data, several interesting observations were made. First, the count rates for each gamma ray $(111,129$ and $414 \mathrm{keV})$ at the three locations were very repeatable for each tank. Variations outside of counting statistics were of the order of a few per cent. The variation in the count rate data due to differing orientations of solution and rings seems to have a minimal effect.

Secondly, when the PMD technique was investigated for these tanks, it was found that all three tanks had essentially the same 111/129 ratio, i.e. no variation with $\mathrm{Pu}$ concentration. As discussed above, the PMD technique relies on a significant difference between the attenuation coefficients for the 111 and $129 \mathrm{keV}$ lines across the $\mathrm{K}$-absorption edge. For the high concentration solutions $(150 \mathrm{~g} / \mathrm{l})$, the difference in the attenuation coefficients is on the order of a factor of two. For the raschig ring tanks, $30 \%$ of the volume is taken up by the rings. The remaining $70 \%$ is low concentration $(<5 \mathrm{~g} / 1) \mathrm{Pu}$ nitrate solution. The code MicroShield v4.22 was used to determine the attenuation coefficients for a bulk material with these volumes of rings and low density $\mathrm{Pu}$ solution. It is found in this case that the attenuation coefficients for the $111 \mathrm{keV}$ and $129 \mathrm{keV}$ lines differ by less than 3\%, not enough for the PMD technique to be used for the low level raschig ring tanks.

Since the PMD densitometry technique could not be utilized, the absolute count rates of the 111, 129, and $414 \mathrm{keV}$ lines were used for calibration and to obtain the assay concentration values. Each of the energy lines provides an independent calibration and thus three assay values were determined for Tank 454 . All three assay values agreed within the measurement uncertainties, so an average of the three was used to determine the final assay value of $1.92 \mathrm{~g} / 1$. Subsequent to the NDA measurements, Tank 454 was drained and DA was performed on the solution. The DA results indicated a concentration of $1.3 \mathrm{~g} / 1$. Further NDA measurements were performed on the "empty" tank and count rates were obtained indicating holdup consistent with the difference between the original NDA value of $1.92 \mathrm{~g} / 1$ and the $1.3 \mathrm{~g} / 1 \mathrm{DA}$ result.

Following the assay measurements for Tank 454, three other raschig ring filled tanks were assayed. Similar to the pencil tank results, the count rates for each of the three energy lines was plotted against DA value and the results are shown in Figure 4 . The very linear relationships that are obtained for all three curves (self absorption at these concentrations is a minimal effect) provide a good confirmation of the original DA value for these tanks.

\section{SUMMARY}

NDA gamma-ray measurements have been used to confirm and estimate fissile solution concentrations of various types of solution tanks at Rocky Flats. For annular, high concentration Pu tanks a "Poor Man's Densitometry" technique has been used with success. For pencil tanks and raschig ring tanks, the count rate for individual gamma-ray lines was used for the concentration estimates. In cases where prior destructive analysis results were available, the NDA data were used to confirm the solution contents of the tanks. In cases where the contents of a tank were unknown or suspected to have been altered, calibrations from other similar tanks were used to produce an assay value for the unknown tank. As the liquid stabilization process continues at Rocky Flats, more of the NDA measured tanks will be drained and sampled. This will allow more complete calibration curves to be constructed for each of the different types of tanks and will allow for improvement in the quality of the NDA measurements.

\section{REFERENCES}

1. S.-T. Hsue, R. Zhu, "Poor Man's Densitometry", INMM 30th Annual Proceedings, July 1989, Vol. XVIII, pp. $806-813$.

2. P. A. Russo, S.-T. Hsue, D. G. Langer, and J. K. Sprinkle, Jr., "Nuclear Safeguards Applications of Energy-Dispersive Absorption-Edge Densitometry", INMM 21st Annual Proceedings, June 1980, Vol. IX, pp. $730-772$.

3. J. G. Fleissner, T. W. Corressel, D. A. Freier, and L. L. Macklin, "TRIFID, A Second Generation Plutonium Isotopic Analysis System", INMM 30th Annual Proceedings, July 1989, Vol. XVIII, pp. 814 820. 


\section{DISCLAIMER}

This report was prepared as an account of work sponsored by an agency of the United States Government. Neither the United States Government nor any agency thereof, nor any of their employees, makes any warranty, express or implied, or assumes any legal liability or responsibility for the accuracy, completeness, or usefulness of any information, apparatus, product, or process disclosed, or represents that its use would not infringe privately owned rights. Reference herein to any specific commercial product, process, or service by trade name, trademark, manufacturer, or otherwise does not necessarily constitute or imply its endorsement, recommendation, or favoring by the United States Government or any agency thereof. The views and opinions of authors expressed herein do not necessarily state or reflect those of the United States Government or any agency thereof. 